\title{
Novel Echocardiographic Indices for Assessing the Left Main Coronary Artery in Children With Kawasaki Disease
}

\author{
Elaheh Malakan Rad, ${ }^{1,2,}$ Iran Malekzadeh, ${ }^{1,2}$ Vahid Ziaee, ${ }^{1,2,3}$ Raheleh Rajabi, ${ }^{2}$ and Zohreh Shahabi ${ }^{2}$ \\ ${ }^{1}$ Department of Pediatrics, Tehran University of Medical Sciences, Tehran, IR Iran \\ ${ }^{2}$ Children's Medical Center, Pediatric Center of Excellence, Tehran, IR Iran \\ ${ }^{3}$ Pediatric Rheumatology Research Group, Rheumatology Research Center, Tehran University of Medical Sciences, Tehran, IR Iran \\ "Corresponding author: Elaheh Malakan Rad, Children's Medical Center, Pediatric Center of Excellence, Tehran, IR Iran. Tel: +98-2166911029; +98-2166428998, Fax: \\ +98-2166923054; +98-2166929235, E-mail: erad@tums.ac.ir
}

Received 2016 April 02; Accepted 2016 May 08.

\begin{abstract}
Background: Kawasaki disease (KD) is the most common cause of acquired myocardial infarction in children. Coronary artery involvement is the most serious feature of this vasculitis syndrome. Timely diagnosis of coronary artery involvement is of utmost importance since it can prevent long-term morbidity and mortality. The current methods for the diagnosis of coronary artery dilation in KD are inconsistent and are also not capable of detecting all the abnormal coronary arteries or the so-called occult dilations present.

Objectives: The aim of this study was to determine the sensitivity and specificity of three novel allometric indices for the diagnosis of left main coronary artery (LMCA) involvement in KD.

Methods: We performed a prospective case-control study in 69 children ( 38 with KD and 31 healthy children). All the followed up patients underwent two complete echocardiographic examinations at the time of admission and 4 - 6 weeks later. We measured the size of the LMCA, coronary sinus (CS) and aorta (A) and calculated the LMCA/CS, LMCA/A and LMCA/CS/A ratios. We also calculated the cut-off scores for each index using receiver operating characteristic curves both in the acute phase and 4 - 6 weeks later.

Results: In the acute phase, the cut-off scores for the LMCA/A ratio was > 0.23; LMCA/CS, > 0.44; and LMCA/CS/A, > 0.03. This implied $60 \%$ sensitivity and $80 \%$ specificity for the detection of abnormal LMCA in KD. Four to six weeks after the acute phase, the LMCA/A cut-off score was > 0.23; LMCA/CS, > 0.73; and LMCA/CS/A, > 0.73. This implied 100\% sensitivity and $100 \%$ specificity for the detection of abnormal LMCA. There was a significant decrease in the size of the CS in comparison with the control group (1.92 $\pm 0.363 \mathrm{~mm}$; $\mathrm{P}$ $=0.007$ and 0.023).

Conclusions: The LMCA/A, LMCA/CS and LMCA/CS/A ratios seem to provide simple and patient-specific indices for the detection of abnormal LMCA in KD, both in the acute and subacute phase. Further, a decrease in the size of the CS may imply a decrease in coronary artery flow in the acute and subacute phases of KD.
\end{abstract}

Keywords: Kawasaki Disease, Coronary Aretry, Echocardiography

\section{Background}

Kawasaki disease (KD) is the most common cause of acquired coronary artery disease and myocardial infarction in children (1). Coronary artery involvement is the most serious complication of this vasculitis syndrome $(2,3)$. There are various echocardiographic criteria for the diagnosis of coronary artery involvement. These criteria are based on either absolute values set according to age in accordance with the values recommended by the ministry of health and welfare of Japan, or Z scores obtained by various methods (4-7). Recently, a few studies reported the ratio of the size of the coronary arteries to that of the aortic annulus in healthy children $(8,9)$. Timely recognition of coronary artery involvement is important to prevent the devastating cardiac complications of $\mathrm{KD}(10,11)$.
However, after more than four decades of the first KD report by Dr. Tomisaku Kawasaki in 1974, there is no international consensus on the criteria for diagnosing abnormal coronary arteries in KD (12-15). Investigators have reported the limitations of the known methods for assessing coronary artery abnormalities $(16,17)$. The main limitation of using $\mathrm{Z}$ scores is that the $\mathrm{Z}$ score varies with different methods of calculation even when the same set of absolute values is used. Moreover, there is yet no consensus on the appropriate method for calculating $Z$ scores $(5,6$, 18-22). The other drawback with $Z$ scores is that one always needs access to the nomograms or a $\mathrm{Z}$ score calculator in order to be able to classify a coronary artery as "normal" or "abnormal." There is therefore a need for a feasible and reliable method for determining the "normality" of the size of the coronary arteries in $\operatorname{KD}(23,24)$. 


\section{Objectives}

Based on the delicate mathematical proportions of the various structures of the human body (such as the McGoon ratio), we investigated the sensitivity and specificity of three novel echocardiographic indices by measuring the diameter of three relevant vessels, i.e., the left main coronary artery (LMCA), the coronary sinus (CS) and aorta (A). We calculated the ratio of the internal diameter of the LMCA to the internal diameter of the CS and aortic annulus. We compared our results with the results of three currently used methods of $Z$ score calculation for LMCA in children $(5,6,25)$. Another objective of this study was to define the cut-off scores for these indices for differentiating between normal and abnormal LMCA in children with KD.

\section{Methods}

Between January 2013 and January 2015, a prospective case-control study was performed on 38 children with KD and 31 age- and sex-matched normal children at the Pediatrics Center of Excellence. The control group consisted of age- and sex-matched infants and children who were diagnosed with a normal heart and referred for evaluation of a murmur, palpitation or cardiac evaluation prior to participation in competitive sports.

Consecutively admitted patients who met the diagnostic criteria for KD were enrolled (4). Children with any of the following conditions were excluded from the study: 1) febrile illness other than confirmed $\mathrm{KD}(26), 2$ ) coexistence of any congenital heart disease except for patent foramen ovale and mild mitral valve prolapse without mitral valve regurgitation, 3) history of previous $\mathrm{KD}, 4$ ) any other congenital or acquired heart disease that could lead to coronary artery dilation such as systemic-onset juvenile rheumatoid arthritis and sickle-cell disease $(27,28), 5)$ any associated genetic or congenital abnormality, and 6) cardiac arrhythmia.

All the patients underwent complete M-mode, twodimensional color Doppler echocardiography with the EKO 7 Cardiovascular Ultrasound System (Samsung Medison Co. Ltd.). The procedure was performed by a single senior pediatric cardiologist (EMR) or a senior pediatric cardiology fellow (RR) within 24 hours of admission and 4 - 6 weeks later. Chloral hydrate syrup was administered at a dose of $50 \mathrm{mg} / \mathrm{kg}$ to irritable and uncooperative patients with KD. All measurements were performed according to the guidelines reported by Lopez and his colleagues (29). Evaluation of coronary arteries was performed as described earlier (30). The internal diameter of the left coronary artery and ascending aorta was measured as described before in all the study groups (31).
Figure 1. Measurement of the Diameter of the Coronary Sinus

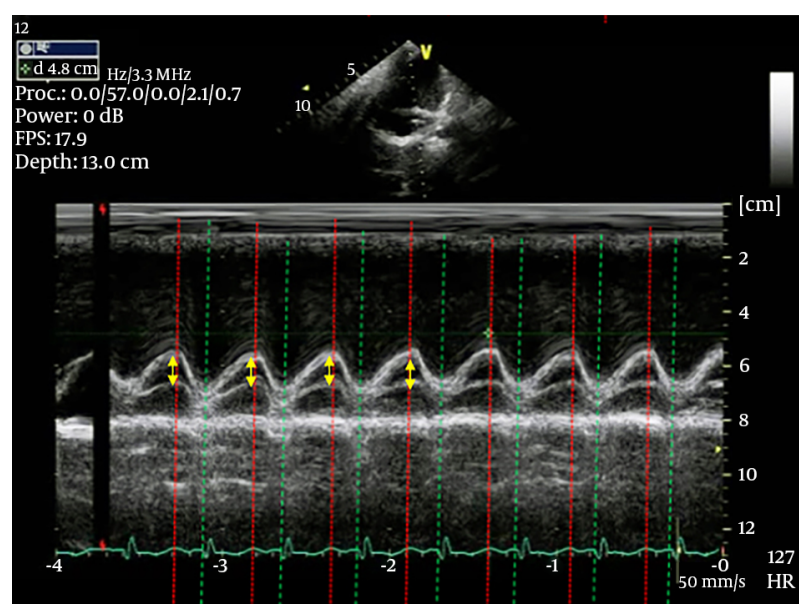

The largest diameter measured for the coronary sinus (coincident with the onset of QRS on the ECG scan) was measured, and the average value from five consecutive cardiac cycles was calculated.

The diameter of the coronary sinus was measured next to the ventricular septum in the modified four-chamber view, as shown in Figure 1, by M-mode echocardiography. The diameter of the aorta was measured according to the method described by Goldstein et al. at segment one of the aorta (32). Each measurement was repeated for three to five consecutive beats using M-mode echocardiography at a sweep speed of $100 \mathrm{~mm} / \mathrm{s}$. The average value of the recordings was calculated. The largest size recorded for each cycle was considered as the final value for all three vessels.

We calculated the three allometric indices of the LMCA in the case and control groups as shown below:

$\mathrm{LCA} / A=\frac{\text { Left main coronary artery }}{\text { aorta }}$

$\mathrm{LCA} / \mathrm{CS}=\frac{\text { Left main coronary artery }}{\text { coronary sinus }}$

$\mathrm{LCA} / \mathrm{CS} / A=\frac{\text { Left main coronary artery }}{\frac{\text { coronary sinus }}{\text { aorta }}}$

We excluded three patients after the start of the study. In the case of the first patient, the urine culture was positive for..., and the other two patients had been subsequently diagnosed with systemic-onset juvenile rheumatoid arthritis.

The remaining 35 patients underwent complete echocardiographic examination. The second echocardiographic examination was carried out 4 to 6 weeks later. Twelve patients were lost to follow up because they were not referred to the hospital again. The profile of the study 
Table 1. Receiver Operating Characteristic (ROC) Analysis of the Left Main Coronary Artery Based on Various Definitions of Normal and Abnormal

\begin{tabular}{lcc}
\hline Number of Groups & Abnormal LMCA Group & Normal LMCA Group \\
\hline $\mathbf{1}$ & A & C \\
$\mathbf{2}$ & B & C \\
$\mathbf{3}$ & A1 & A2 \\
$\mathbf{4}$ & B1 & B2 \\
$\mathbf{5}$ & A1 & C \\
$\mathbf{6}$ & B1 & C \\
\hline 7 & A1 & A2, B2 and C \\
$\mathbf{8}$ & B1 & A2, B2 and C \\
\hline
\end{tabular}

group is shown in Figure 2. Patients were classified as "normal" only after a thorough echocardiographic evaluation excluded the presence of any dilation or thrombosis in the right and left coronary arteries and their major branches, including the left anterior descending coronary artery. We compared our findings with the currently available $\mathrm{Z}$ score datasets. For ethical reasons, we did not use coronary angiography as the gold standard for comparison. The age and sex distribution of the control group was almost similar to that of the patient group.

\subsection{Statistical Analysis}

All data were analyzed using SPSS version 18 (SPSS Inc., Chicago). Descriptive analysis of age; weight; height; and size of the LMCA, CS and aorta was performed. We used the general linear model to compare the $\mathrm{Z}$ scores. P values $\leq 0.05$ were considered to indicate statistical significance. We compared the results of the case and control groups using an independent t-test. We used receiver operating characteristic (ROC) curves for determination of the cut-off scores for each of the indices. For each ratio, ROC analysis was used to compare participants with "normal" coronary arteries and "abnormal" LMCA (Table 1). Therefore, eight ROC curves were drawn for each of the ratios, and a total of 24 curves were drawn for all the three ratios.

\section{Results}

4.1. Demographic Data and Absolute Values for the LMCA, CS, and $A$

The demographic data for both the case and control groups are presented in Table 2 . The absolute values of the internal diameter of the LMCA, CS and ascending aorta are presented in Table 3.

\section{2. $L M C A / A, L M C A / C S$ and $L M C A / C S / A$ Ratios}

The values are shown in Table 4.

\subsection{Comparison of the Calculated Z Scores}

General linear model analysis revealed a significant difference among the $\mathrm{Z}$ scores obtained using the various methods (Table 5).

\subsection{Cut-Off Scores for the LMCA/A, LMCA/CS and LMCA/CS/A Ra- tios}

We drew eight ROC curves, as shown in Figure 3. The cut-off scores for each index are tabulated in Tables 6 - 8 .

\subsection{Cut-Off Scores of the Three Ratios}

For LMCA/A, we found that a cut-off score of 0.23 in the acute phase had $60 \%$ sensitivity and $80 \%$ specificity. Further, a cut-off score of 0.23 had $100 \%$ sensitivity and $100 \%$ specificity in the subacute phase.

A cut-off score of 0.44 for LMCA/CS in the acute phase had $62 \%$ sensitivity and $81 \%$ specificity, while a cut-off score of 0.73 had $100 \%$ sensitivity and $100 \%$ specificity in the follow-up echocardiographic examination conducted 4 - 6 weeks later.

For LMCA/CS/A, a cut-off score of 0.03 in the acute phase had $62 \%$ sensitivity and $81 \%$ specificity. Further, at $4-6$ weeks, a cut-off score of 0.73 had $100 \%$ sensitivity and $100 \%$ specificity.

\section{Discussion}

\subsection{The Novel Indices and Their Cut-Off Values}

We introduce three novel indices for assessment of the LMCA in children with KD. Our study showed that an LMCA/A ratio of $>0.23$, an LMCA/CS ratio of $>0.44$ and an LMCA/CS/A ratio of $>0.03$ has $60 \%$ sensitivity and $80 \%$ specificity for the detection of LMCA abnormalities in patients with KD who are in the very acute phase of the disease. Only one of these indices (LMCA/A) has already been reported in normal children (9). Zhang and his colleagues reported a mean $( \pm S D)$ value of $0.24 \pm 0.06$ for the LMCA/A ratio in 506 healthy children aged 1 to 11 years in China (10), whereas Tan and his colleagues reported a value of $0.15 \pm$ $0.02 \mathrm{~mm}$ for the LMCA/A ratio in 390 normal Asian infants and children ranging in age from 2 months to 8 years. As can be seen, our value $(0.13 \pm 0.03)$ is close to that reported by the latter study (11). 


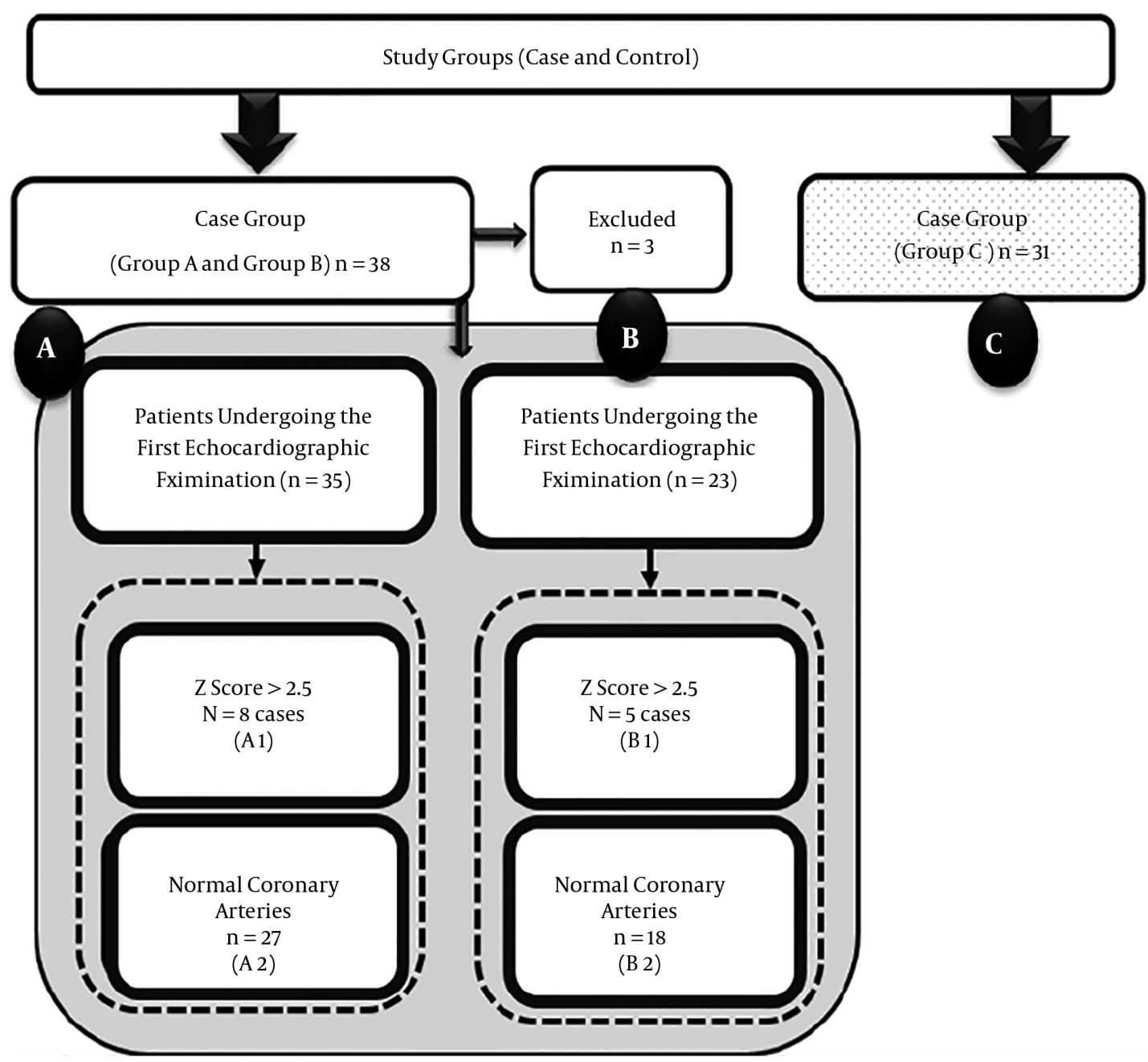

Figure 2. Categorization of the Study Population, Including Both Case and Control Groups, into the Three Main Groups (A, B and C)

Table 2. Demographic Data of the Study Group (Case and Control Groups)

\begin{tabular}{lcc}
\hline & Case & Control \\
\hline Age, range & 4 months to 11 years & 2 months to 11 years \\
Age, mean \pm SD & $39.89 \pm 32 / 969$ & $53.74 \pm 38 / 179$ \\
Weight, kg, mean \pm SD & $14.19 \pm 5.603$ & $17.06 \pm 8 / 966$ \\
Female/male ratio, No. $(\%)$ & $15(42.9) / 20(57.1)$ & 0.119 \\
\hline
\end{tabular}

\subsection{Disadvantages of the Currently Used Methods}

There are three main methods for measurement of the coronary arteries in KD: The first method is based on the absolute values of the internal diameter of coronary arteries, according to the criteria of the ministry of health of Japan. The second measurement method is based on body- surface-area-adjusted $\mathrm{Z}$ scores, and the third method is a combination of the two above measurements, such as the one recommended by the american heart association (33).

There are two main shortcomings of the current methods of $\mathrm{Z}$ score calculation. The main limitation is the difference in the $\mathrm{Z}$ scores obtained with the different meth- 
Table 3. Absolute Values of the Internal Diameter of the Left Main Coronary Artery, Coronary Sinus and Ascending Aorta at the Sino-Tubular Junction

\begin{tabular}{|c|c|c|c|c|c|}
\hline & \multicolumn{2}{|c|}{ Case } & \multirow{2}{*}{$\begin{array}{l}\text { Control } \\
\text { (Group C) }\end{array}$} & \multirow{2}{*}{$\begin{array}{c}\text { P Value (Group } \\
\text { A vs. Group C) }\end{array}$} & \multirow{2}{*}{$\begin{array}{l}\text { P Value (Group } \\
\text { B vs. Group C) }\end{array}$} \\
\hline & $\begin{array}{l}\text { First Echocardiographic } \\
\text { Examination (Group A) }\end{array}$ & $\begin{array}{l}\text { Second Echocardiographic } \\
\text { Examination (Group B) }\end{array}$ & & & \\
\hline $\begin{array}{l}\text { Internal diameter of the left main } \\
\text { coronary artery }(\mathrm{mm})\end{array}$ & $2.59 \pm 1.32$ & $2.99 \pm 2.09$ & $1.92 \pm 0.363$ & 0.007 & 0.023 \\
\hline $\begin{array}{l}\text { Internal diameter of the coronary } \\
\text { sinus }(\mathbf{m m})\end{array}$ & $4.70 \pm 1.87$ & $5.31 \pm 2.29$ & $5.87 \pm 2.09$ & 0.019 & 0.356 \\
\hline $\begin{array}{l}\text { Internal diameter of the } \\
\text { ascending aorta }(\mathrm{mm})\end{array}$ & $13.95 \pm 2.93$ & $13.63 \pm 3.68$ & $14.50 \pm 3.90$ & 0.515 & 0.407 \\
\hline
\end{tabular}

Table 4. Values of the LMCA/A, LMCA/CS and LMCA/CS/A Ratios

\begin{tabular}{|c|c|c|c|c|c|}
\hline \multirow[t]{2}{*}{ Indices } & \multicolumn{3}{|c|}{ Case Groups $^{\mathrm{a}}$} & \multirow{2}{*}{$\begin{array}{c}\text { Control Group } \\
\text { Findings on Echocardiographic } \\
\text { Examination }\end{array}$} & \multirow[t]{2}{*}{ P Value } \\
\hline & $\begin{array}{l}\text { First Echocardiographic } \\
\text { Examination (Group A) }\end{array}$ & P Value & $\begin{array}{l}\text { Second Echocardiographic } \\
\text { Examination (Group B) }\end{array}$ & & \\
\hline LMCA/A & $0.19 \pm 0.10$ & 0.004 & $0.23 \pm 0.15$ & $0.13 \pm 0.03$ & 0.007 \\
\hline LMCA/CS & $0.62 \pm 0.38$ & $<0.001$ & $0.60 \pm 0.32$ & $0.36 \pm 0.13$ & 0.003 \\
\hline LMCA/CS/A & $0.05 \pm 0.32$ & 0.002 & $0.05 \pm 0.025$ & $0.027 \pm 0.01$ & 0.003 \\
\hline
\end{tabular}

${ }^{\mathrm{a}}$ Values are presented as mean $\pm \mathrm{SD}$

Table 5. Comparison of the Different Methods of Z Score Calculation in the Case and Control Groups

\begin{tabular}{|c|c|c|c|c|c|c|}
\hline Group & LMCA (mm) & $\begin{array}{l}\text { Z Scores with Our } \\
\text { Method }^{\mathrm{a}}\end{array}$ & $\begin{array}{l}\text { Z Scores Based on the } \\
\text { McCrindle et al. Method }^{\text {a }}\end{array}$ & $\begin{array}{l}\text { Z Scores Based on the } \\
\text { Dallaire et al. Method }^{\text {a }}\end{array}$ & $\begin{array}{l}\text { Z Scores Based on the } \\
\text { Olivieri et al. Method }^{\mathbf{a}}\end{array}$ & PValue \\
\hline $\mathbf{A}$ & $2.59 \pm 1.32$ & $0.19 \pm 0.10$ & $0.76 \pm 3.40$ & $1.52 \pm 3.66$ & $0.63 \pm 2.37$ & $<0.0001$ \\
\hline B & $2.99 \pm 2.09$ & $0.62 \pm 0.38$ & $1.70 \pm 5.34$ & $2.50 \pm 5.70$ & $1.01 \pm 3.03$ & 0.003 \\
\hline C & $1.91 \pm 0.36$ & $0.05 \pm 0.32$ & $-1.13 \pm 0.86$ & $-0.55 \pm 0.99$ & $-0.81 \pm 1.22$ & $<0.0001$ \\
\hline
\end{tabular}

${ }^{\mathrm{a}}$ Values are presented as mean $\pm \mathrm{SD}$.

Table 6. Cut-Off Scores for the LMCA/A Ratio Under All Eight Conditions*

\begin{tabular}{|c|c|c|c|c|}
\hline Normal Versus Abnormal Group(s) & Cut-Off Score & Sensitivity & Specificity & PValue \\
\hline Groups A versus C & 0.159 & 60 & 81 & 0.005 \\
\hline Groups B versus C & 0.145 & 65 & 62 & 0.010 \\
\hline Groups A1 versus C & 0.238 & 87.5 & 100 & $<0.001$ \\
\hline Groups B1 versus C & 0.232 & 100 & 100 & $<0.001$ \\
\hline Groups B1 versus B2 & 0.235 & 100 & 83 & 0.004 \\
\hline Groups A1 versus A2, B2 and C & 0.250 & 87.5 & 100 & $<0.001$ \\
\hline Groups B1 versus A2, B2 and C & 0.235 & 100 & 94 & 0.001 \\
\hline
\end{tabular}

ods even when the same set of values are used, and the second limitation is the lack of consensus on the appropriate method of choice.

As shown in Table 5, we found a disparity in the results obtained with the different methods of Z score calculation both in the case and control groups. Although no other study similar to ours has been performed so far, the disadvantages of these methods have been reported by others 

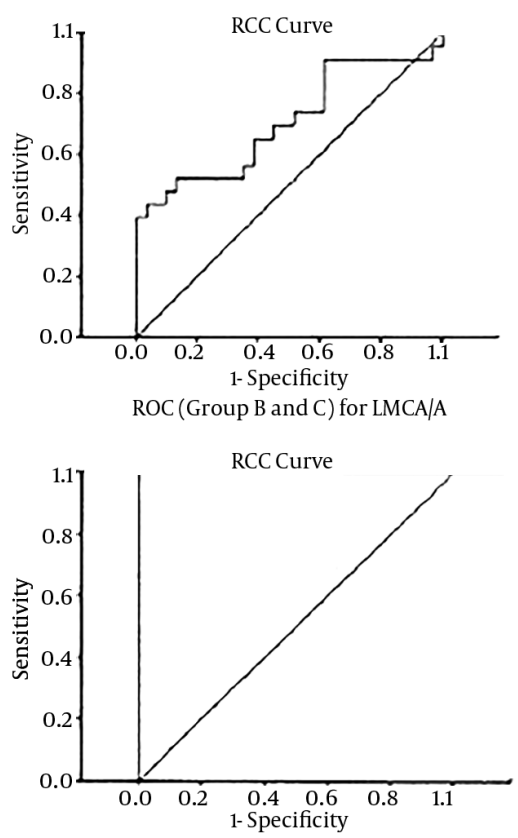

ROC (Group B1 and C) for LMCA/A

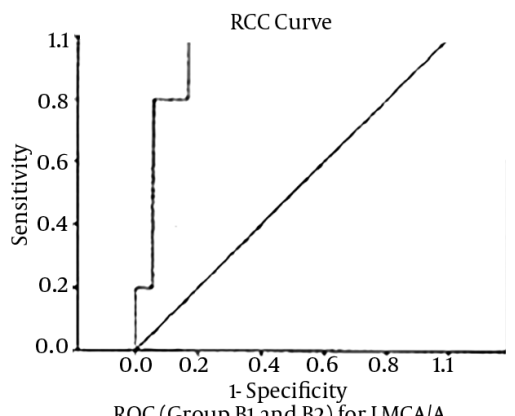

ROC (Group B1 and B2) for LMCA/A

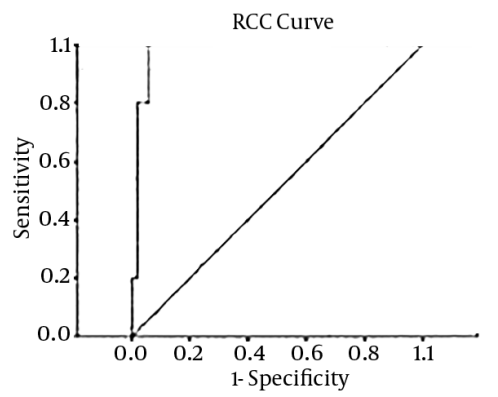

ROC (Group B1 and All A2, B2 and C) for LMCA/A

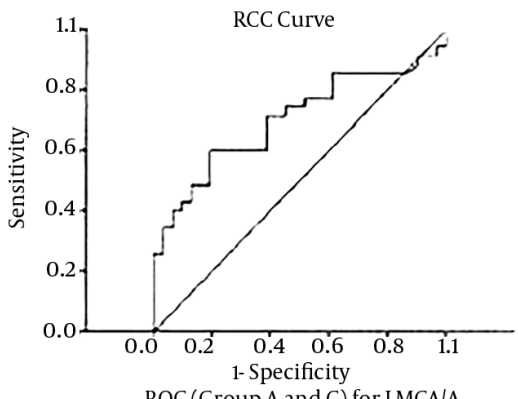

ROC (Group A and C) for LMCA/A

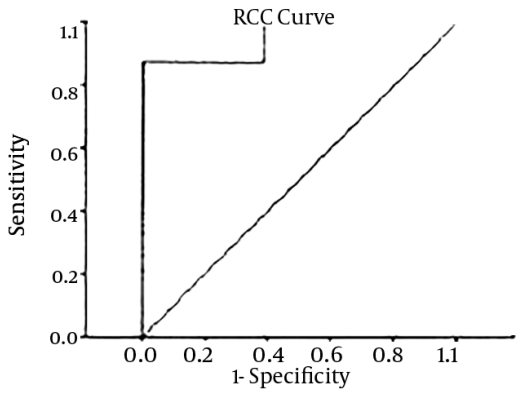

ROC (Group A1 and C) for LMCA/A

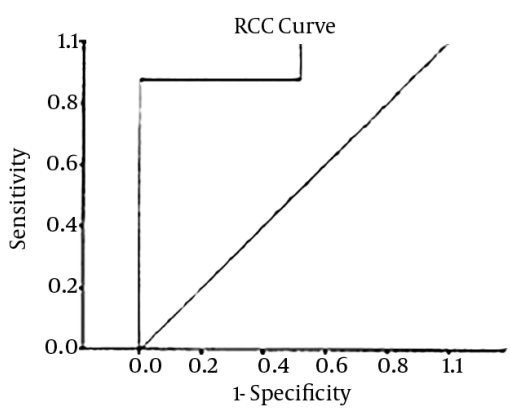

ROC (Group A1 and A2) for LMCA/A

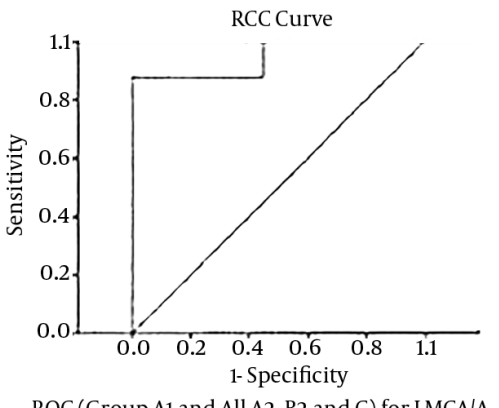

Figure 3. ROC Curves for the LMCA/A Ratio of the Indicated Groups

(5). For example, de Zorzi and his colleagues indicated that using the criteria of the ministry of health of Japan for differentiation between normal and abnormal coronary arteries can lead to underestimation of coronary artery in- volvement in KD (16). Further, Manlhiot et al. retrospectively studied 1356 children with KD over a 17-year period (7) and concluded that some coronary artery abnormalities are missed by the AHA classification. Moreover, they found 
Table 7. Cut-Off Scores for the LMCA/CS Ratio Under All Eight Conditions*

\begin{tabular}{|c|c|c|c|c|}
\hline Normal Versus Abnormal Group(s) & Cut-Off Score & Sensitivity & Specificity & PValue \\
\hline Groups A versus C & 0.443 & 62 & 81 & $<0.001$ \\
\hline Groups B versus C & 0.398 & 69 & 71 & 0.002 \\
\hline Groups A1 versus C & 0.835 & 87.5 & 100 & $<0.001$ \\
\hline Groups B1 versus C & 0.728 & 100 & 100 & $<0.001$ \\
\hline Groups A1 versus A2 & 0.894 & 87.5 & 100 & $<0.001$ \\
\hline Groups B1 versus B2 & 0.712 & 100 & 89 & 0.002 \\
\hline Groups A1 versus A2, B2 and C & 0.894 & 87.5 & 100 & $<0.001$ \\
\hline Groups B1 versus A2, B2 and C & 0.729 & 100 & 96 & $<0.001$ \\
\hline
\end{tabular}

Table 8. Cut-Off Scores for the LMCA/CS/A Ratio Under All Eight Conditions*

\begin{tabular}{|c|c|c|c|c|}
\hline Normal Versus Abnormal Group(s) & Cut-Off Score & Sensitivity & Specificity & PValue \\
\hline Groups A versus C & 0.031 & 63 & 75 & 0.002 \\
\hline Groups B versus C & 0.031 & 60 & 74 & 0.004 \\
\hline Groups A1 versus C & 0.056 & 87.5 & 97 & $<0.001$ \\
\hline Groups B1 versus C & 0.056 & 100 & 97 & $<0.001$ \\
\hline Groups A1 versus A2 & 0.059 & 87.5 & 96 & $<0.001$ \\
\hline Groups B1 versus B2 & 0.059 & 100 & 89 & 0.006 \\
\hline Groups A1 versus A2, B2 and C & 0.059 & 87.5 & 97 & $<0.001$ \\
\hline Groups B1 versus A2, B2 and C & 0.056 & 100 & 94 & $<0.001$ \\
\hline
\end{tabular}

that the $\mathrm{Z}$ scores of subcategories sometimes overlap, as a result of which giant coronary artery aneurysms can be missed. Dallaire and his co-workers conducted a study on 1033 normal children in which they provided the predicted values and threshold values for the $\mathrm{Z}$ score for the LMCA/AO ratio (5). In another study, they introduced the term "occult dilation," which indicated a decrease in the size of coronary arteries despite consistent normal scores; this was observed in 63 of 197 children with KD (31). Hence, there is a need for consensus on the method of choice for the calculation of $\mathrm{Z}$ scores for coronary arteries, including the LMCA, in KD.

Another disadvantage of these methods is that a nomogram is required at all times in order to assess the normality of the LMCA.

\subsection{Advantages of the Three Novel Allometric Indices}

The indices used in the present study are well-tailored and individualized to each patient's specific anatomical features, as the coronary artery is compared to the relevant vessels in the same person. Further, this method is user friendly and simple to use. The cut-off scores are simple to memorize and there is no need for nomograms and $\mathrm{Z}$ score calculators to determine the normality of the size of the LMCA.

\subsection{Decrease in the Size of the CS and Its Implications}

An interesting finding of this study was that the diameter of the CS had decreased in size in the very acute phase of KD. This may reflect a decrease in coronary blood flow in the LMCA in the very acute phase of KD in children. Cicala et al. showed a decrease in coronary flow reserve in children with a previous history of KD (34). Moreover, Ohkubo and colleagues reported that decrease in shear stress and disturbance in coronary blood flow may lead to the formation of aneurysms in the coronary arteries of these patients (35). However, to date, no study has quantified coronary blood flow in children in the very acute phase of KD. Considering the physiologic and anatomic features of the CS, there may be some merit in measuring the size of the CS in $\mathrm{KD}(36,37)$.

\subsection{Conclusion}

This study shows that the three indices measured here are reliable for the detection of abnormalities in the LMCA 
and do not require the use of $Z$ score nomograms. Our findings also indicate that the size of the CS is significantly decreased in the very acute phase of KD. This may indicate alterations in coronary blood flow due to acute pathologic changes in the vessel wall. This paradoxical observation between the size of the coronary artery and coronary sinus warrants further investigation.

\subsection{Limitations}

This study has several limitations that need to be addressed in future studies. Although several patients were evaluated simultaneously by both the echocardiographers and their diagnosis was the same, interobserver agreement was not calculated using the kappa statistic. The fellow who performed the analysis was a well-trained senior fellow who at the time of submission had graduated. The second limitation is the small number of patients, which limits the generalizability of our findings. Thus, future studies should be conducted in which these cut-off values are applied for the detection of dilated coronary arteries in children with KD.

\section{Acknowledgments}

The authors appreciate the cooperation of the patients and their parents, who provided their consent for this study.

\section{References}

1. Jamieson N, Singh-Grewal D. Kawasaki disease: a clinician's update. Int J Pediatr. 2013;2013:645391.2.

2. Belay ED, Maddox RA, Holman RC, Curns AT, Ballah K, Schonberger LB. Kawasaki syndrome and risk factors for coronary artery abnormalities: United States, 1994-2003. Pediatr Infect Dis J. 2006;25(3):245-9. doi: 10.1097/01.inf.0000202068.30956.16. [PubMed: 16511388].

3. Rowley AH. The Complexities of the Diagnosis and Management of Kawasaki Disease. Infect Dis Clin North Am. 2015;29(3):525-37. doi: 10.1016/j.idc.2015.05.006. [PubMed: 26154665].

4. Newburger JW, Takahashi M, Gerber MA, Gewitz MH, Tani LY, Burns JC, et al. Diagnosis, treatment, and long-term management of Kawasaki disease: a statement for health professionals from the Committee on Rheumatic Fever, Endocarditis and Kawasaki Disease, Council on Cardiovascular Disease in the Young, American Heart Association. Circulation. 2004;110(17):2747-71. doi: 10.1161/01.CIR.0000145143.19711.78. [PubMed: 15505111].

5. Dallaire F, Dahdah N. New equations and a critical appraisal of coronary artery $\mathrm{Z}$ scores in healthy children. J Am Soc Echocardiogr. 2011;24(1):60-74. doi: 10.1016/j.echo.2010.10.004. [PubMed: 21074965].

6. Olivieri L, Arling B, Friberg M, Sable C. Coronary artery Z score regression equations and calculators derived from a large heterogeneous population of children undergoing echocardiography. J Am Soc Echocardiogr. 2009;22(2):159-64. doi: 10.1016/j.echo.2008.11.003. [PubMed: 19084373].

7. Manlhiot C, Millar K, Golding F, McCrindle BW. Improved classification of coronary artery abnormalities based only on coronary artery z-scores after Kawasaki disease. Pediatr Cardiol. 2010;31(2):242-9. doi: 10.1007/s00246-009-9599-7. [PubMed: 20024653].
8. Tremoulet AH, Jain S, Jaggi P, Jimenez-Fernandez S, Pancheri JM, Sun $\mathrm{X}$, et al. Infliximab for intensification of primary therapy for Kawasaki disease: a phase 3 randomised, double-blind, placebo-controlled trial. Lancet. 2014;383(9930):1731-8.

9. Dominguez SR, Anderson MS, El-Adawy M, Glode MP. Preventing coronary artery abnormalities: a need for earlier diagnosis and treatment of Kawasaki disease. Pediatr Infect Dis J. 2012;31(12):1217-20. doi: 10.1097/INF.0b013e318266bcf9. [PubMed: 22760536].

10. Zhang YQ, Chen SB, Huang GY, Zhang HY, Huang MR, Wang SS, et al Coronary artery indexed diameter and $\mathrm{z}$ score regression equations in healthy Chinese Han children. J Clin Ultrasound. 2015;43(1):39-46. doi: 10.1002/jcu.22176. [PubMed: 24975134].

11. Tan TH, Wong KY, Cheng TK, Heng JT. Coronary normograms and the coronary-aorta index: objective determinants of coronary artery dilatation. Pediatr Cardiol. 2003;24(4):328-35. doi: 10.1007/s00246-0020300-7. [PubMed: 12360388].

12. Kawasaki T, Kosaki F, Okawa S, Shigematsu I, Yanagawa H. A new infantile acute febrile mucocutaneous lymph node syndrome (MLNS) prevailing in Japan. Pediatrics. 1974;54(3):271-6. [PubMed: 4153258].

13. Kawasaki T, Naoe S. History of Kawasaki disease. Clin Exp Nephrol. 2014;18(2):301-4. doi: 10.1007/s10157-013-0877-6. [PubMed: 24595558].

14. Kawasaki T. Kawasaki disease. Int J Rheum Dis. 2014;17(5):597-600. doi: 10.1111/1756-185X.12408. [PubMed: 25042617].

15. Burns JC. The riddle of Kawasaki disease. $N$ Engl J Med. 2007;356(7):659-61. doi: 10.1056/NEJMp068268. [PubMed: 17301296].

16. de Zorzi A, Colan SD, Gauvreau K, Baker AL, Sundel RP, Newburger JW. Coronary artery dimensions may be misclassified as normal in Kawasaki disease. J Pediatr. 1998;133(2):254-8.

17. Crystal MA, Manlhiot C, Yeung RS, Smallhorn JF, McCrindle BW. Coronary artery dilation after Kawasaki disease for children within the normal range. Int J Cardiol. 2009;136(1):27-32. doi: 10.1016/j.ijcard.2008.04.019. [PubMed:18619690].

18. Mawad W, Drolet C, Dahdah N, Dallaire F. A review and critique of the statistical methods used to generate reference values in pediatric echocardiography. J Am Soc Echocardiogr. 2013;26(1):29-37. doi 10.1016/j.echo.2012.09.021. [PubMed: 23140845].

19. Dallaire F, Bigras JL, Prsa M, Dahdah N. Bias related to body mass index in pediatric echocardiographic Z scores. Pediatr Cardiol. 2015;36(3):667-76. doi: 10.1007/s00246-014-1063-7. [PubMed: 25388631].

20. Cantinotti M, Scalese M, Molinaro S, Murzi B, Passino C. Limitations of current echocardiographic nomograms for left ventricular, valvular, and arterial dimensions in children: a critical review. J Am Soc Echocardiogr. 2012;25(2):142-52. doi: 10.1016/j.echo.2011.10.016. [PubMed: 22101087].

21. Fairbanks EF. Children's Proportions for Artists. Fairbanks Art and Books; 2012.

22. Ronai C, Hamaoka-Okamoto A, Baker AL, de Ferranti SD, Colan SD, Newburger JW, et al. Coronary Artery Aneurysm Measurement and Z Score Variability in Kawasaki Disease. J Am Soc Echocardiogr 2016;29(2):150-7. doi:10.1016/j.echo.2015.08.013. [PubMed: 26386984].

23. Baur $\mathrm{H}$, Leuenberger $\mathrm{C}$. Analysis of ratios in multivariate morphometry. Syst Biol. 2011;60(6):813-25. doi: 10.1093/sysbio/syro61. [PubMed: 21828084].

24. Burton RF. Human allometry: adult bodies are more nearly geometrically similar than regression analysis has suggested. Med Hypotheses. 2010;74(1):15-7. doi:10.1016/j.mehy.2009.08.009. [PubMed:19726135].

25. McCrindle BW, Li JS, Minich LL, Colan SD, Atz AM, Takahashi M, et al. Coronary artery involvement in children with Kawasaki disease: risk factors from analysis of serial normalized measurements. Circulation. 2007;116(2):174-9. doi: 10.1161/CIRCULATIONAHA.107.690875. [PubMed: 17576863]. 
26. Bratincsak A, Reddy VD, Purohit PJ, Tremoulet AH, Molkara DP, Frazer $\mathrm{JR}$, et al. Coronary artery dilation in acute Kawasaki disease and acute illnesses associated with Fever. Pediatr Infect Dis J. 2012;31(9):924-6. doi: 10.1097/INF.0b013e31826252b3. [PubMed: 22673140].

27. Binstadt BA, Levine JC, Nigrovic PA, Gauvreau K, Dedeoglu F, Fuhlbrigge RC, et al. Coronary artery dilation among patients presenting with systemic-onset juvenile idiopathic arthritis. Pediatrics. 2005;116(1):89-93. doi: 10.1542/peds.2004-2190. [PubMed: 15930186].

28. Doshi AR, Pauliks LB. Increased left main coronary artery dimensions in children with sickle cell disease. Pediatr Cardiol. 2013;34(4):954-8. doi: 10.1007/s00246-012-0587-y. [PubMed: 23188180].

29. Lopez L, Colan SD, Frommelt PC, Ensing GJ, Kendall K, Younoszai AK, et al. Recommendations for quantification methods during the performance of a pediatric echocardiogram: a report from the Pediatric Measurements Writing Group of the American Society of Echocardiography Pediatric and Congenital Heart Disease Council. J Am Soc Echocardiogr. 2010;23(5):465-95. doi: 10.1016/j.echo.2010.03.019. [PubMed: 20451803]

30. Brown LM, Duffy CE, Mitchell C, Young L. A practical guide to pediatric coronary artery imaging with echocardiography. J Am Soc Echocardiogr. 2015;28(4):379-91. doi: 10.1016/j.echo.2015.01.008. [PubMed: 25691000].

31. Dallaire F, Fournier A, Breton J, Nguyen TD, Spigelblatt L, Dahdah N. Marked variations in serial coronary artery diameter measures in Kawasaki disease: a new indicator of coronary involvement. J Am Soc Echocardiogr. 2012;25(8):859-65. doi: 10.1016/j.echo.2012.05.019. [PubMed: 22824173].
32. Goldstein SA, Evangelista A, Abbara S, Arai A, Asch FM, Badano LP, et al. Multimodality imaging of diseases of the thoracic aorta in adults: from the American Society of Echocardiography and the European Association of Cardiovascular Imaging: endorsed by the Society of Cardiovascular Computed Tomography and Society for Cardiovascular Magnetic Resonance. J Am Soc Echocardiogr. 2015;28(2):119-82. doi: 10.1016/j.echo.2014.11.015. [PubMed: 25623219].

33. Newburger JW, Takahashi M, Gerber MA, Gewitz MH, Tani LY, Burns JC, et al. Diagnosis, treatment, and long-term management of Kawasaki disease: a statement for health professionals from the Committee on Rheumatic Fever, Endocarditis, and Kawasaki Disease, Council on Cardiovascular Disease in the Young, American Heart Association. Pediatrics. 2004;114(6):1708-33. doi: 10.1542/peds.2004-2182. [PubMed: 15574639].

34. Cicala S, Galderisi M, Grieco M, Lamberti A, Cosimi R, Pellegrini F, et al. Transthoracic echo-Doppler assessment of coronary microvascular function late after Kawasaki disease. Pediatr Cardiol. 2008;29(2):3217. doi: 10.1007/s00246-007-9030-1. [PubMed: 17726625].

35. Ohkubo T, Fukazawa R, Ikegami E, Ogawa S. Reduced shear stress and disturbed flow may lead to coronary aneurysm and thrombus formations. Pediatr Int. 2007;49(1):1-7. doi: 10.1111/j.1442-200X.2007.02312.x. [PubMed: 17250496].

36. Abbas U, Brownlee J, Adebo D. Giant coronary sinus aneurysm and multiple coronary artery aneurysms in a pediatric patient. Images Paediatr Cardiol. 2015;17(1):1-3. [PubMed: 26236373].

37. D'Cruz IA, Shirwany A. Update on echocardiography of coronary sinus anatomy and physiology. Echocardiography. 2003;20(1):87-95. [PubMed: 12848705]. 